\title{
Comparative Clinical Utility of Tumor Genomic Testing and Cell- Free DNA in Metastatic Breast Cancer
}

\author{
Kara N. Maxwell, MD, PhD ${ }^{1}$, Danielle Soucier-Ernst, MPH, MBE ${ }^{2}$, Emin Tahirovic, $\mathrm{PhD}^{3}$, \\ Andrea B. Troxel, ScD ${ }^{7}$, Candace Clark, BS ${ }^{2}$, Michael Feldman, MD, PhD $^{4}$, Christopher \\ Colameco, MPH $^{2}$, Bijal Kakrecha, BS ${ }^{1}$, Melissa Langer, BS ${ }^{8}$, David Lieberman, MS $^{4}$, \\ Jennifer J.D. Morrissette, PhD $^{4}$, Matt R. Paul, BS ${ }^{5}$, Tien-chi Pan, MS $^{5}$, Yee Stephanie ${ }^{1}$, \\ Natalie Shih, MBChB, MPH ${ }^{4}$, Erica Carpenter, MBA, PhD ${ }^{1,2}$, Lewis A. Chodosh, MD, \\ $\mathrm{PhD}^{2,5,6}$, and Angela DeMichele, MD, MSCE${ }^{1,2,3}$
}

\begin{abstract}
${ }^{1}$ Department of Medicine, Division of Hematology-Oncology, Perelman School of Medicine at the University of Pennsylvania, Philadelphia, Pennsylvania ${ }^{2}$ Abramson Cancer Center, Perelman School of Medicine at the University of Pennsylvania, Philadelphia, Pennsylvania ${ }^{3}$ Department of Biostatistics and Epidemiology, Perelman School of Medicine at the University of Pennsylvania, Philadelphia, Pennsylvania ${ }^{4}$ Department of Pathology and Laboratory Medicine, Perelman School of Medicine at the University of Pennsylvania, Philadelphia, Pennsylvania ${ }^{5}$ Department of Cancer Biology, Perelman School of Medicine at the University of Pennsylvania, Philadelphia, Pennsylvania ${ }^{6}$ Department of Medicine, Division of Endocrinology, Diabetes and Metabolism at the Perelman School of Medicine at the University of Pennsylvania, Philadelphia, Pennsylvania ${ }^{7}$ Department of Population Health, NYU School of Medicine, New York, New York ${ }^{8}$ University of Maryland School of Medicine, Baltimore, Maryland
\end{abstract}

\begin{abstract}
Purpose-Breast cancer metastases differ biologically from primary disease; therefore, metastatic biopsies may assist in treatment decision-making. Commercial genomic testing of both tumor and circulating tumor DNA have become available clinically, but utility of these tests in breast cancer management remains unclear.
\end{abstract}

Methods-Patients undergoing a clinically indicated metastatic tumor biopsy were consented to the ongoing METAMORPH registry. Tumor and blood were collected at time of disease progression before subsequent therapy, and patients were followed for response on subsequent treatment. Tumor testing $(n=53)$ and concurrent cell-free DNA $(n=32)$ in a subset of patients was performed using CLIA-approved assays.

Results-The proportion of patients with a genomic alteration was lower in tumor than in blood ( $69 \%$ vs $91 \%$; $\mathrm{p}=0.06$ ). After restricting analysis to alterations covered on both platforms, $83 \%$ of tumor alterations were detected in blood, while $90 \%$ of blood alterations were detected in tumor. Mutational load specific for the panel genes was calculated for both tumor and blood. Time to progression on subsequent treatment was significantly shorter for patients whose tumors had high

Corresponding Author: Angela DeMichele, MD, MSCE, Perelman Center for Advanced Medicine, 10th floor South Tower, 3400 Civic Center Boulevard, Philadelphia, PA 19104, (215) 614-1850 (Phone) | (215)615-3349 (Fax), angela.demichele@ uphs.upenn.edu. 
panel-specific mutational load (HR $0.31,95 \% \mathrm{CI} 0.12-0.78$ ) or a TP53 mutation (HR=0.35, 95\% CI 0.20-0.79), after adjusting for stage at presentation, hormone receptor status, prior treatment type and number of lines of metastatic treatment.

Conclusions-Treating oncologists must distinguish platform differences from true biological heterogeneity when comparing tumor and cfDNA genomic testing results. Tumor and concurrent cfDNA contribute unique genomic information in metastatic breast cancer patients, providing potentially useful biomarkers for aggressive metastatic disease.

\section{Keywords}

metastatic breast cancer; liquid biopsy; cell-free DNA; genomic testing; massively parallel sequencing

\section{INTRODUCTION}

Breast cancer is the most common malignancy and the second leading cause of cancer death in women[1]. Approximately $20 \%$ of women diagnosed with the disease ultimately recur and over 40,000 women die annually of metastatic breast cancer (MBC)[1]. Standard treatment is guided by expression of hormone receptors (HR) or the epidermal growth factor receptor-2 (Her2), with sequential endocrine therapies initially in most $\mathrm{HR}+$ disease, chronic anti-Her2 therapy (with or without chemotherapy) in Her2+ disease, and sequential chemotherapy in triple negative and endocrine-resistant disease[2].

Receptor expression and genetic changes can differ between the primary and metastases[3], as tumors continue to evolve both stochastically and in response to treatment; therefore, analyzing biomarkers of metastatic tumors has potential clinical utility. Currently, there are numerous commercial assays that can detect genomic alterations in tumors and shed tumor DNA in the circulation (cfDNA). A number of studies have reported on the spectrum of mutations identified in primary and metastatic breast cancer[4-7], and similar recurrent genomic alterations have been identified both in tumor and in blood[8-13]. However, the clinical utility of this information in treatment decision-making has not been established, despite the theoretical potential to improve prognostication, expand therapeutic targets[1416], or enable tracking of therapeutic response[17],

In order to gain insight into the potential clinical utility of commercial CLIA-approved tumor and cfDNA genomic assays in the management of metastatic breast cancer in the clinic, we sought to evaluate the hypotheses that (1) cfDNA could be used in place of tumor biopsy to identify therapeutic and response biomarkers and (2) specific mutations or panelspecific measures of mutational burden or heterogeneity would be associated with response to subsequent therapy. We analyzed data from patients undergoing concurrent assays at the time of clinical confirmatory biopsy. The aims of the current analysis were to (1) determine concordance of genomic alterations in shared genes on different clinical tumor and cfDNA panels, (2) identify reasons for discordance that impact clinical interpretation by treating oncologists, and (3) identify potential genomic alterations that could be useful in predicting treatment response. 


\section{METHODS}

\section{Patients, Informed Consent, and Study Design}

Patients undergoing metastatic tumor biopsy for clinical reasons (either to confirm histology or receptor status) were prospectively identified as per inclusion criteria (Supplementary Methods) for the METAMORPH ("Metastatic Markers of Recurrent Tumor Phenotype") Study, which is a registry for commercial testing and additional collection of research tumor and blood samples. The protocol was approved by the Institutional Review Board (IRB) at the University of Pennsylvania. Tumor and blood samples were collected from identified patients within one month of each other and prior to the start of the patient's subsequent treatment (Supplementary Figure 1). Patients subsequently underwent standard-of-care treatment determined by their treating physician. Physicians and patients received results of the genomic assays approximately $2-3$ weeks after biopsy and collection, and were not mandated to use this information for treatment selection. Patients were tracked prospectively with data collected regarding date of last treatment, reason for discontinuing treatment, and best response (based upon clinical and radiographic clinical determinations).

\section{Tumor Genomic Testing}

Genomic tumor testing was performed at the Center for Personalized Diagnostics (CPD) at the University of Pennsylvania Department of Pathology using a CLIA-approved targeted gene panel. Formalin-fixed paraffin embedded (FFPE) tumor blocks were obtained. A Hematoxylin and Eosin stained slide was used to select areas containing at minimum 10\% tumor for macrodissection and isolation of DNA. Tumor DNA was analyzed on one of two clinically available Illumina amplicon based massively parallel sequencing panels (San Diego, CA), When possible, the "CPD_Full" panel was performed, which contained 203 amplicons covering mutational hotspots of 47 cancer related genes (Illumina TruSeq Cancer Panel). If insufficient DNA was obtained for the full panel, the "CPD_PPP" was performed, which contains a subset of 77 amplicons covering portions of 20 cancer related genes (Supplementary Table 1-2). Samples were sequenced on an Illumina miSeq to a minimum mean coverage of 1000X[18]. Data were analyzed through an in-house bioinformatics pipeline to identify single nucleotide variants (SNVs), insertion/deletion (indels) and amplifications[18]. The minimum allele frequency (AF) detectable by the tumor assay was 눙. Forty-four patients had CPD_Full and nine patients had CPD_PPP tumor testing.

\section{cfDNA Genomic Testing}

Whole blood was sent to GuardantHealth,, a CLIA-certified, College of American Pathologists-accredited laboratory (Redwood City, CA) for the Guardant360 cfDNA test in a subset of thirty-five patients who were included in a 10-patient pilot study (funded by Guardant Health) or enrolled on the Guardant Health registration study. When the Guardant study ended, samples were no longer sent for evaluation to avoid having patients incur clinical cost. cfDNA was isolated for digital sequencing as previously described[19]. Hotspots for targeted genes were sequenced. Over the course of the study, the panel underwent changes; "GH_v1" contained genomic regions of 54 cancer related genes and "GH_v2" contained the genomic regions of 68 cancer genes (Supplementary Tables 1-2). Samples were sequenced using a proprietary ultra-deep sequencing assay to a mean 
coverage of 15000X[19]. Data were analyzed through a custom bioinformatics pipeline to identify SNVs and, in selected genes, indels, amplifications and fusions[19]. The minimum AF detectable by the cfDNA was $\geq 0.1 \%$. Twenty-eight patients had GH_v1 testing and seven had GH_v2 testing.

\section{Analysis of sequencing data}

The tumor genomic assay reported SNVs, indels, and amplifications classified as variants of uncertain significance (VUS) or pathogenic in all covered genes. The cfDNA assay reported all identified SNVs and amplifications in EGFR, ERBB2, and MET. All variants were classified according to American College of Medical Genetics and Genomic guidelines[20,21]. cfDNA variants not reported in the tumor were examined in the raw sequencing data by the study team. Tumor variants not reported in cfDNA assay were examined by the Guardant Health team. Only the variants in 18 shared genes on both CPD assays for patients with tumor results and the 46 shared genes on both cfDNA assays for patients with cfDNA results were analyzed.

As small hotspot panels are unlikely to accurately determine overall mutational burden as measured by whole genome or whole exome sequencing, "panel-specific mutational loads" were calculated for both tumor and cfDNA data. Tumor panel-specific mutational load was calculated by summing the total number of variants in the 18 shared genes found on both the CPD_PPP and CPD_Full panels for each sample. cfDNA panel-specific mutational load was calculated by summing the total number of variants in the 46 shared genes found on both the GH_v1 and GH_v2 panels for each sample. We determined the average number of variants in these genes per subject in The Cancer Genome Atlas (TCGA) primary breast tumors $(n=963)$. On average, TCGA subjects had $1 \pm 1$ variants in the shared genes on the tumor assay and $2 \pm 1$ variants in the shared genes on the cfDNA assay (Supplementary Table 3). We then classified patients in this study as having a high panel-specific mutational load if they had mutational loads in shared genes two standard deviations above the mean on the particular assay, i.e., three or more tumor variants and/or four or more cfDNA variants. Mutational heterogeneity was defined as the presence of a mutation that would be covered and reported by both assays but only found by one assay in a patient.

\section{Statistical analyses}

Means of continuous variables were compared between analysis groups using a two-tailed Student's t-test. Outliers were excluded based on Grubb's test (extreme studentized deviate test). Comparisons of rates in different groups were conducted using a Fisher's exact test of significance. Time to progression (TTP) was defined as the number of days from the start of treatment to the first indication of progressive disease, by either scan or clinical assessment. Kaplan Meier curves were calculated to estimate TTP; comparison of TTP between analysis groups used the logrank test. Cox proportional hazards models were constructed to assess the relationship between TTP and genomic variables of interest, adjusting for other determinants of clinical outcome, including receptor status, type of treatment and numbers of lines of therapy. All tests were two-sided and conducted in Stata (version 11) and R (version 3.3.1) at a significance level of 0.05. Results are reported in accordance with REMARK guidelines. 


\section{RESULTS}

\section{Study population}

Seventy patients were enrolled and tumor biopsies were obtainable in 66 (94\%)

(Supplementary Figure 2, Table 1). Receptors were obtained for 62 patients. Eight of the patients (20\%) had discordant receptor status between the primary and metastatic tumor (Supplementary Table 4). Five patients lost HR expression, two gained HR expression, and one lost Her2 expression. The average time between primary and metastatic diagnosis was significantly longer in patients with discordant receptors compared to those with concordant receptors (128 versus 73 months, $\mathrm{p}=0.002)$. Fifty-three (80\%) had successful tumor genomic testing, and 35 had successful cfDNA testing. The characteristics of those with cfDNA were similar to those in the overall cohort (Table 1).

\section{Mutation and variant spectra of tumor biopsies and cfDNA}

Within the 53 patients in the tumor cohort, 65 alterations in 14 genes were found on the tumor genomic report (Table 2, Figure 1). Among the 32 patients with concurrently measured tumor and cfDNA (tumor/cfDNA cohort), 39 alterations in 6 genes were reported from the tumor assay; 93 alterations were reported in 27 genes from the cfDNA assay (Table 2, Supplementary Figure 3). TP53 and PIK3CA were the most commonly mutated genes identified in each assay. Addition of the cfDNA assay did not increase the number of patients identified to have a PIK3CA mutation or ERBB2 (HER2) amplification. However, it did identify two additional patients with TP53 mutations, one additional patient with an activating ERBB2 mutation, three patients with $J A K 2$ mutations and one patient with $E G F R$ and $M E T$ co-amplification. The cfDNA did not identify six variants found in tumor only two TP53 mutations, two PIK3CA mutations, an ERBB2 amplification and a SMAD4VUS. At least one pathogenic mutation was identified in $69 \%$ and $72 \%$ of patients on the tumor and cfDNA assays, respectively. Thus, the addition of the cfDNA assay to tumor genomic testing resulted in a negligible increase in the number of patients with a pathogenic mutation. When all variants were considered, $69 \%$ of patients had at least one variant identified in tumor and this increased to $91 \%$ with the addition of the cfDNA assay. As small genomic panels likely do not accurately identify whole genome reported mutational burden(ref), panel-specific mutational load was determined and high versus low cutoffs determined by analysis of TCGA data for the panel-specific genes. Using this measure, 9\% of the tumor cohort and $21 \%$ of the tumor/cfDNA cohort were classified as having a high panel-specific mutational load on one of their assays. Only two patients in the tumor/cfDNA cohort had a high panel-specific mutational load in the tumor alone, and the cfDNA assay identified six additional patients with a high panel-specific mutational load.

\section{Concordance between tumor and cfDNA assays}

Among the tumor/cfDNA cohort, 100 variants in total were found. Using data available on clinical reports, only 29 of 100 variants (29\%) were concordantly identified by both assays: four amplifications in ERBB2 and EGFR and 25 missense mutations in PIK3CA, TP53, and $E R B B 2$ (Figure 2a). A substantial fraction (53 of 71,75\%) of discordant results occurred due to differences in test coverage or variant reporting practices of the clinical laboratory. Forty-five variants identified in cfDNA were in genomic regions not covered by the tumor 
assay (45\% of identified variants) (Figure 2a). It is important to note that some variants were in genes reported on the coverage list of each assay but in exons or introns that were not covered for that gene via discussion with the clinical laboratory. Eight variants were covered and identified by both assays but of a variant class not clinically reported by the clinical laboratory's reporting practices (Figure 2a).

Ultimately, 47 variants were covered and reportable by both assays performed in a given patient and 18 variants were only detected by one assay, giving a nontechnical discordance rate of $38 \%$ (18 of 47 variants). Six variants were identified only in tumor, including one ERBB2 amplification and pathogenic mutations or VUSs in PIK3CA (2), TP53 (2), and $S M A D 4$ (1). Twelve variants were only identified in cfDNA: EGFR and MET amplifications, three pathogenic mutations in $T P 53$, three $J A K 2 \mathrm{p}$.V617F mutations, and one VUS each in EGFR, JAK3, NPM1, and RET. Fifteen of 32 patients had mutational heterogeneity between assays. Four patients with mutational heterogeneity had excess mutations in tumor, and twelve patients with mutational heterogeneity had excess mutations in cfDNA.

\section{Allele frequency differences between concordant and discordant variants}

Allele frequencies (AF) in tumor-only genomic testing are affected by stromal and inflammatory cell DNA and in cfDNA testing by normal leukocyte DNA; therefore, we would not expect similar AF in tumor and cfDNA. However, we evaluated the relative AF to identify potential factors that may contribute to discordance in identification of alterations. For concordant variants, $89 \%$ were identified at a higher AF in tumor versus cfDNA (Figure 2b). Four variants were found at similar AF: a $S M A D 4$ VUS at approximately $50 \%$ AF in both assays, and one TP53 and two PIK3CA hotspot mutations found at 20-30\% AF in both tumor and cfDNA. Considering all variants covered by both assays, the AF of concordant and discordant tumor variants ranged from $8.0-87.7 \%$ and $32.5-49.5 \%$, respectively. In comparison, the AF of concordant and discordant cfDNA variants ranged from 0.4-50.4\% and $0.2-0.8 \%$, respectively (Figure $2 \mathrm{~b}$ ). The AF were not significantly different between concordant and discordant tumor variants; however, the AF of discordant cfDNA variants was significantly lower than concordant variants (Figure 2c). Given this observation, the raw tumor sequencing data were reanalyzed, and evidence of the cfDNA variant was found in at least five reads for eight of the ten discordant SNVs with AF ranging from $0.03-0.45 \%$ in the tumor (Supplementary Table 5). For amplifications, all four concordant amplifications were found at similar levels in both tumor and cfDNA (Figure 2b). The two discordant cfDNA amplifications were very low level, below 3-fold, whereas the discordant tumor amplification was a high-level amplification (Figure 2c). There was no evidence of the two amplifications in the tumor testing. Overall, therefore, incorporating reanalysis of raw sequencing data, the nontechnical discordance rate between tumor and cfDNA was $21 \%$.

\section{Effects of genomic profiles on response to subsequent therapy}

We examined whether genomic alterations were associated with outcomes from conventional treatment of MBC patients by determining time to progression (TTP) for the therapy immediately following genomic assessment. Treatment decisions were not based upon the results of these assays. Adjusted for stage, hormone receptor status, and prior 
treatment type and number of lines, patients with high panel-specific mutational load had a significantly shorter TTP than those with a low mutational load (HR=0.31 95\%CI 0.12-0.78, $\mathrm{p}=0.0112$ ) (Figure 3a, Supplementary Table 6). For tumor alterations, the low versus high panel-specific mutational load groups had $0.9( \pm 0.8)$ versus $3.3( \pm 0.6)$ variants $\left(\mathrm{p}<10^{-6}\right)$. For cfDNA alterations, the low versus high panel-specific mutational load groups had $1.3( \pm 0.9)$ variants versus $6.1( \pm 3.2)$ variants $\left(\mathrm{p}<10^{-11}\right)$. In addition, the presence of a TP53 mutation in either the tumor or cfDNA was associated with a significantly shorter TTP (HR $=0.35$, 95\% CI 0.20-0.79, $\mathrm{p}=0.00374$ ) (Figure 3b, Supplementary Table 6). No association was seen with PIK3CA mutation status (Supplementary Figure 4a). Finally, for patients in the tumor/ cfDNA cohort, there was no association between mutational heterogeneity and TTP (Supplementary Figure 4b).

\section{DISCUSSION}

Commercial CLIA-approved assays for genomic testing of tumors and cfDNA are clinically available for patients with breast cancer, though there is little data evaluating the interpretation of different genomic assays performed in a clinical oncology setting. In the METAMORPH study, we systematically evaluated results of two different commercially available clinical testing panels from tumors compared to cfDNA obtained concurrently in a subset of MBC patients. We delineate a number of purely technical aspects of genomic profiling that resulted in a high rate of discordant results. True (nontechnical) discordance was shown for $21 \%$ of variants detected, and in both directions, with $10 \%$ of tumor variants not detected in cfDNA and $17 \%$ of cfDNA variants not detected in tumor. These results suggest that neither assay captures the full range of potentially actionable mutations for an individual patient. Finally, for conventional, non-targeted therapy, a high panel-specific mutational load measured by a small targeted panel or a TP53 mutation were associated with a shorter TTP of therapy in MBC patients, suggesting that such patients will ultimately exhaust therapeutic options sooner for this incurable condition.

Prior studies of concordance between tumor and cfDNA in metastatic cancer patients have been mainly restricted to analysis of pathogenic mutations and/or evaluation of identical genomic assays in both tissue sources. Studies evaluating pathogenic mutations identified by the same panel in metastatic breast cancer patients have found concordance rates above $70 \%$ [22-24], and a recent prospective study using different clinically available panels confirmed these findings[9]. Studies in mixed tumor types have shown both lower[25,26] and higher[27,28] rates of concordance. For example, in the prospective MOSCATO trial of 283 patients, only $50 \%$ of variants identified by the same panel were concordant between tumor and cfDNA . In this study we wished to evaluated non-identical assays that are clinically available, and we initially show only a $29 \%$ concordance rate between tumor and cfDNA. A large proportion of the discordance was not biological and due to technical reasons such as differences in test coverage of genes, laboratory variant reporting practices, variant classification, and allele frequency thresholds for detection based on total sequencing depth. These factors are extremely important for practicing oncologists to understand when ordering and interpreting the results of such tests in order to avoid erroneous conclusions about potential therapeutic targets, or the gain or loss of specific mutations or overall changes in mutational burden under the pressure of therapy. 
The six variants identified in five patients' tumors that were not found in cfDNA were all high allele frequency mutations and therefore it is possible these results are due to differences in the shedding of tumor DNA in those individuals. However, three of these five patients had other variants that were concordant between tumor and cfDNA, suggesting differences in ability to shed DNA between either different clonal populations of a tumor or different metastatic tumor sites. Reanalysis of cfDNA variants initially felt to represent true discordance showed that the majority of discordant cfDNA SNVs were due a lower variant allele frequency detection cutoff of the cfDNA assay. Given the challenges of using next generation based sequencing for copy number analysis, one must be careful to make this assumption for the low-level amplifications, of which no evidence was seen in the raw tumor sequencing data. Furthermore, of the low frequency mutations identified in cfDNA only, three were in $J A K 2$ and three in TP53, both of which are clonal hematopoiesis genes[29] and therefore could be due to mutated DNA from clonal lymphocyte populations.

Few tools exist to guide optimal treatment selection or sequence in MBC patients. Antigens, such as CA 27-29, and circulating tumor cells[30], while recommended within the ASCO guidelines to assist in decision-making[31], are of limited clinical value. The clinical utility of genomic assays have further been called into question by the recent IMAGE trial which was closed due to protocol-specified interim futility analysis[9] Our finding that a high panel-specific mutational load in the metastatic lesion in either the cfDNA (occurring in $25 \%$ of patients) or tumor (occurring in $9 \%$ of patients) is predictive of poor response to conventional therapy independent of receptor status is novel and should be confirmed. Supporting this finding is a recent analysis of 560 primary ER+ tumors showed that $29 \%$ of the patients had a high mutational load and this was associated with decreased overall survival[32]. While it is unlikely that the mutational burden on these small captures will be fully concordant with whole genome or whole exome calculated mutational burden, our results suggest that clinically useful information on mutational burden can still be identified using panel-specific cutoffs. Prior studies have also suggested that TP53 mutations in primary breast cancer predict poor overall survival[33,34], and our data confirm this observation in MBC patients as well. Therefore, analysis of mutational load or TP53 mutations in tumors and/or cfDNA may be a useful clinical biomarker of therapy response in MBC patients.

There are a number of caveats to our study. First, the data reflect a small number of patients; however, these data provide the first in-depth analysis of clinically obtained and evaluated genomic tumor profiling with concurrent cfDNA analysis in a real-world clinical oncology setting. In addition, tumor genomic profiling was performed on FFPE derived samples using two different genomic panels, which may bias results as compared to analysis using fresh frozen tissue or identical panels; however, as this was a clinical utility study, we wished to perform genomic profiling as is standardly done clinically.

In summary, our data provide new insights into the differences in mutation detection between tumor and cfDNA in metastatic breast cancer patients that are important to the interpretation and application of these commonly used assays, and identifies panel-specific measures of mutational load as a potentially useful biomarker in patient management. 


\section{Supplementary Material}

Refer to Web version on PubMed Central for supplementary material.

\section{Acknowledgments}

We would like to acknowledge the research cases as well as the funding agencies that made this research possible and the assistance of Guardant Health in performing the cfDNA assays. This work was supported by the Translational Center of Excellence in Breast Cancer of the Abramson Cancer Center, University of Pennsylvania. K.N.M. and A.D.M had full access to all of the data in the study and take responsibility for the integrity of the data and the accuracy of the data analysis. The authors declare that they have no conflict of interest. The experiments performed within comply with the current ethical standards and laws of the United States of America.

\section{References}

1. Howlader, N., Noone, AM., Krapcho, M., Garshell, J., Miller, D., Altekruse, SF., Kosary, CL., Yu, M., Ruhl, J., Tatalovich, Z., Mariotto, A., Lewis, DR., Chen, HS., Feuer, EJ., Cronin, KA. SEER Cancer Statistics Review, 1975-2012. 2015. http://seer.cancer.gov/csr/1975_2012/

2. Gradishar WJ, Anderson BO, Balassanian R, Blair SL, Burstein HJ, Cyr A, Elias AD, Farrar WB, Forero A, Giordano SH, Goetz M, Goldstein LJ, Hudis CA, Isakoff SJ, Marcom PK, Mayer IA, McCormick B, Moran M, Patel SA, Pierce LJ, Reed EC, Salerno KE, Schwartzberg LS, Smith KL, Smith ML, Soliman H, Somlo G, Telli M, Ward JH, Shead DA, Kumar R. Breast Cancer Version 2.2015. J Natl Compr Canc Netw. 2015; 13(4):448-475. [PubMed: 25870381]

3. Zardavas D, Irrthum A, Swanton C, Piccart M. Clinical management of breast cancer heterogeneity. Nat Rev Clin Oncol. 2015; 12(7):381-394. DOI: 10.1038/nrclinonc.2015.73 [PubMed: 25895611]

4. Cancer Genome Atlas Network. Comprehensive molecular portraits of human breast tumours. Nature. 2012; 490(7418):61-70. DOI: 10.1038/nature11412 [PubMed: 23000897]

5. Nik-Zainal S, Alexandrov LB, Wedge DC, Van Loo P, Greenman CD, Raine K, Jones D, Hinton J, Marshall J, Stebbings LA, Menzies A, Martin S, Leung K, Chen L, Leroy C, Ramakrishna M, Rance R, Lau KW, Mudie LJ, Varela I, McBride DJ, Bignell GR, Cooke SL, Shlien A, Gamble J, Whitmore I, Maddison M, Tarpey PS, Davies HR, Papaemmanuil E, Stephens PJ, McLaren S, Butler AP, Teague JW, Jonsson G, Garber JE, Silver D, Miron P, Fatima A, Boyault S, Langerod A, Tutt A, Martens JW, Aparicio SA, Borg A, Salomon AV, Thomas G, Borresen-Dale AL, Richardson AL, Neuberger MS, Futreal PA, Campbell PJ, Stratton MR. Mutational processes molding the genomes of 21 breast cancers. Cell. 2012; 149(5):979-993. DOI: 10.1016/j.cell.2012.04.024 [PubMed: 22608084]

6. Nik-Zainal S, Van Loo P, Wedge DC, Alexandrov LB, Greenman CD, Lau KW, Raine K, Jones D, Marshall J, Ramakrishna M, Shlien A, Cooke SL, Hinton J, Menzies A, Stebbings LA, Leroy C, Jia M, Rance R, Mudie LJ, Gamble SJ, Stephens PJ, McLaren S, Tarpey PS, Papaemmanuil E, Davies HR, Varela I, McBride DJ, Bignell GR, Leung K, Butler AP, Teague JW, Martin S, Jonsson G, Mariani O, Boyault S, Miron P, Fatima A, Langerod A, Aparicio SA, Tutt A, Sieuwerts AM, Borg A, Thomas G, Salomon AV, Richardson AL, Borresen-Dale AL, Futreal PA, Stratton MR, Campbell PJ. The life history of 21 breast cancers. Cell. 2012; 149(5):994-1007. DOI: 10.1016/j.cell. 2012.04.023 [PubMed: 22608083]

7. Morganella S, Alexandrov LB, Glodzik D, Zou X, Davies H, Staaf J, Sieuwerts AM, Brinkman AB, Martin S, Ramakrishna M, Butler A, Kim HY, Borg A, Sotiriou C, Futreal PA, Campbell PJ, Span PN, Van Laere S, Lakhani SR, Eyfjord JE, Thompson AM, Stunnenberg HG, van de Vijver MJ, Martens JW, Borresen-Dale AL, Richardson AL, Kong G, Thomas G, Sale J, Rada C, Stratton MR, Birney E, Nik-Zainal S. The topography of mutational processes in breast cancer genomes. Nature communications. 2016; 7:11383.doi: 10.1038/ncomms11383

8. Andre F, Bachelot T, Commo F, Campone M, Arnedos M, Dieras V, Lacroix-Triki M, Lacroix L, Cohen P, Gentien D, Adelaide J, Dalenc F, Goncalves A, Levy C, Ferrero JM, Bonneterre J, Lefeuvre C, Jimenez M, Filleron T, Bonnefoi H. Comparative genomic hybridisation array and DNA sequencing to direct treatment of metastatic breast cancer: a multicentre, prospective trial (SAFIR01/UNICANCER). Lancet Oncol. 2014; 15(3):267-274. DOI: 10.1016/ S1470-2045(13)70611-9 [PubMed: 24508104] 
9. Parsons HA, Beaver JA, Cimino-Mathews A, Ali SM, Axilbund J, Chu D, Connolly RM, Cochran RL, Croessmann S, Clark TA, Gocke CD, Jeter SC, Kennedy MR, Lauring J, Lee J, Lipson D, Miller VA, Otto GA, Rosner GL, Ross JS, Slater S, Stephens PJ, VanDenBerg DA, Wolff AC, Young LE, Zabransky DJ, Zhang Z, Zorzi J, Stearns V, Park BH. Individualized Molecular Analyses Guide Efforts (IMAGE): A Prospective Study of Molecular Profiling of Tissue and Blood in Metastatic Triple-Negative Breast Cancer. Clin Cancer Res. 2017; 23(2):379-386. DOI: 10.1158/1078-0432.CCR-16-1543 [PubMed: 27489289]

10. Vasan N, Yelensky R, Wang K, Moulder S, Dzimitrowicz H, Avritscher R, Wang B, Wu Y, Cronin MT, Palmer G, Symmans WF, Miller VA, Stephens P, Pusztai L. A targeted next-generation sequencing assay detects a high frequency of therapeutically targetable alterations in primary and metastatic breast cancers: implications for clinical practice. Oncologist. 2014; 19(5):453-458. DOI: 10.1634/theoncologist.2013-0377 [PubMed: 24710307]

11. Roy-Chowdhuri S, de Melo Gagliato D, Routbort MJ, Patel KP, Singh RR, Broaddus R, Lazar AJ, Sahin A, Alvarez RH, Moulder S, Wheler JJ, Janku F, Gonzalez-Angulo AM, Chavez-MacGregor M, Valero V, Ueno NT, Mills G, Mendelsohn J, Yao H, Aldape K, Luthra R, Meric-Bernstam F. Multigene Clinical Mutational Profiling of Breast Carcinoma Using Next-Generation Sequencing. American journal of clinical pathology. 2015; 144(5):713-721. DOI: 10.1309/ AJCPWDEQYCYC92JQ [PubMed: 26486734]

12. Craig DW, O'Shaughnessy JA, Kiefer JA, Aldrich J, Sinari S, Moses TM, Wong S, Dinh J, Christoforides A, Blum JL, Aitelli CL, Osborne CR, Izatt T, Kurdoglu A, Baker A, Koeman J, Barbacioru C, Sakarya O, De La Vega FM, Siddiqui A, Hoang L, Billings PR, Salhia B, Tolcher AW, Trent JM, Mousses S, Von Hoff D, Carpten JD. Genome and transcriptome sequencing in prospective metastatic triple-negative breast cancer uncovers therapeutic vulnerabilities. Molecular cancer therapeutics. 2013; 12(1):104-116. DOI: 10.1158/1535-7163.MCT-12-0781 [PubMed: 23171949]

13. Manso L, Mouron S, Tress M, Gomez-Lopez G, Morente M, Ciruelos E, Rubio-Camarillo M, Rodriguez-Peralto JL, Pujana MA, Pisano DG, Quintela-Fandino M. Analysis of Paired PrimaryMetastatic Hormone-Receptor Positive Breast Tumors (HRPBC) Uncovers Potential Novel Drivers of Hormonal Resistance. PLoS One. 2016; 11(5):e0155840.doi: 10.1371/journal.pone.0155840 [PubMed: 27195705]

14. Meric-Bernstam F, Brusco L, Shaw K, Horombe C, Kopetz S, Davies MA, Routbort M, Piha-Paul SA, Janku F, Ueno N, Hong D, De Groot J, Ravi V, Li Y, Luthra R, Patel K, Broaddus R, Mendelsohn J, Mills GB. Feasibility of Large-Scale Genomic Testing to Facilitate Enrollment Onto Genomically Matched Clinical Trials. J Clin Oncol. 2015; 33(25):2753-2762. DOI: 10.1200/ JCO.2014.60.4165 [PubMed: 26014291]

15. Arnedos M, Vicier C, Loi S, Lefebvre C, Michiels S, Bonnefoi H, Andre F. Precision medicine for metastatic breast cancer-limitations and solutions. Nat Rev Clin Oncol. 2015; 12(12):693-704. DOI: 10.1038/nrclinonc.2015.123 [PubMed: 26196250]

16. Zardavas D, Baselga J, Piccart M. Emerging targeted agents in metastatic breast cancer. Nat Rev Clin Oncol. 2013; 10(4):191-210. DOI: 10.1038/nrclinonc.2013.29 [PubMed: 23459626]

17. Esposito A, Bardelli A, Criscitiello C, Colombo N, Gelao L, Fumagalli L, Minchella I, Locatelli M, Goldhirsch A, Curigliano G. Monitoring tumor-derived cell-free DNA in patients with solid tumors: clinical perspectives and research opportunities. Cancer treatment reviews. 2014; 40(5): 648-655. DOI: 10.1016/j.ctrv.2013.10.003 [PubMed: 24184333]

18. Daber R, Sukhadia S, Morrissette JJ. Understanding the limitations of next generation sequencing informatics, an approach to clinical pipeline validation using artificial data sets. Cancer Genet. 2013; 206(12):441-448. DOI: 10.1016/j.cancergen.2013.11.005 [PubMed: 24528889]

19. Lanman RB, Mortimer SA, Zill OA, Sebisanovic D, Lopez R, Blau S, Collisson EA, Divers SG, Hoon DS, Kopetz ES, Lee J, Nikolinakos PG, Baca AM, Kermani BG, Eltoukhy H, Talasaz A. Analytical and Clinical Validation of a Digital Sequencing Panel for Quantitative, Highly Accurate Evaluation of Cell-Free Circulating Tumor DNA. PLoS One. 2015; 10(10):e0140712.doi: 10.1371/ journal.pone.0140712 [PubMed: 26474073]

20. Maxwell KN, Hart SN, Vijai J, Schrader KA, Slavin TP, Thomas T, Wubbenhorst B, Ravichandran V, Moore RM, Hu C, Guidugli L, Wenz B, Domchek SM, Robson ME, Szabo C, Neuhausen SL, Weitzel JN, Offit K, Couch FJ, Nathanson KL. Evaluation of ACMG-Guideline-Based Variant 
Classification of Cancer Susceptibility and Non-Cancer-Associated Genes in Families Affected by Breast Cancer. Am J Hum Genet. 2016; 98(5):1-17. DOI: 10.1016/j.ajhg.2016.02.024

21. Richards S, Aziz N, Bale S, Bick D, Das S, Gastier-Foster J, Grody WW, Hegde M, Lyon E, Spector E, Voelkerding K, Rehm HL. Standards and guidelines for the interpretation of sequence variants: a joint consensus recommendation of the American College of Medical Genetics and Genomics and the Association for Molecular Pathology. Genet Med. 2015; 17(5):405-424. DOI: 10.1038/gim.2015.30 [PubMed: 25741868]

22. Rothe F, Laes JF, Lambrechts D, Smeets D, Vincent D, Maetens M, Fumagalli D, Michiels S, Drisis S, Moerman C, Detiffe JP, Larsimont D, Awada A, Piccart M, Sotiriou C, Ignatiadis M. Plasma circulating tumor DNA as an alternative to metastatic biopsies for mutational analysis in breast cancer. Ann Oncol. 2014; 25(10):1959-1965. DOI: 10.1093/annonc/mdu288 [PubMed: 25185240]

23. Madic J, Kiialainen A, Bidard FC, Birzele F, Ramey G, Leroy Q, Rio Frio T, Vaucher I, Raynal V, Bernard V, Lermine A, Clausen I, Giroud N, Schmucki R, Milder M, Horn C, Spleiss O, Lantz O, Stern MH, Pierga JY, Weisser M, Lebofsky R. Circulating tumor DNA and circulating tumor cells in metastatic triple negative breast cancer patients. Int J Cancer. 2015; 136(9):2158-2165. DOI: 10.1002/ijc.29265 [PubMed: 25307450]

24. Higgins MJ, Jelovac D, Barnathan E, Blair B, Slater S, Powers P, Zorzi J, Jeter SC, Oliver GR, Fetting J, Emens L, Riley C, Stearns V, Diehl F, Angenendt P, Huang P, Cope L, Argani P, Murphy KM, Bachman KE, Greshock J, Wolff AC, Park BH. Detection of tumor PIK3CA status in metastatic breast cancer using peripheral blood. Clin Cancer Res. 2012; 18(12):3462-3469. DOI: 10.1158/1078-0432.CCR-11-2696 [PubMed: 22421194]

25. Jovelet C, Ileana E, Le Deley MC, Motte N, Rosellini S, Romero A, Lefebvre C, Pedrero M, PataMerci N, Droin N, Deloger M, Massard C, Hollebecque A, Ferte C, Boichard A, Postel-Vinay S, Ngo-Camus M, De Baere T, Vielh P, Scoazec JY, Vassal G, Eggermont A, Andre F, Soria JC, Lacroix L. Circulating Cell-Free Tumor DNA Analysis of 50 Genes by Next-Generation Sequencing in the Prospective MOSCATO Trial. Clin Cancer Res. 2016; 22(12):2960-2968. DOI: 10.1158/1078-0432.CCR-15-2470 [PubMed: 26758560]

26. Strauss WM, Carter C, Simmons J, Klem E, Goodman N, Vahidi B, Romero J, Masterman-Smith M, O'Regan R, Gogineni K, Schwartzberg L, Austin LK, Dempsey PW, Cristofanilli M. Analysis of tumor template from multiple compartments in a blood sample provides complementary access to peripheral tumor biomarkers. Oncotarget. 2016; 7(18):26724-26738. DOI: 10.18632/oncotarget. 8494 [PubMed: 27049831]

27. Kim ST, Lee WS, Lanman RB, Mortimer S, Zill OA, Kim KM, Jang KT, Kim SH, Park SH, Park JO, Park YS, Lim HY, Eltoukhy H, Kang WK, Lee WY, Kim HC, Park K, Lee J, Talasaz A. Prospective blinded study of somatic mutation detection in cell-free DNA utilizing a targeted 54gene next generation sequencing panel in metastatic solid tumor patients. Oncotarget. 2015; 6(37): 40360-40369. DOI: 10.18632/oncotarget.5465 [PubMed: 26452027]

28. Chae YK, Davis AA, Carneiro BA, Chandra S, Mohindra N, Kalyan A, Kaplan J, Matsangou M, Pai S, Costa R, Jovanovic B, Cristofanilli M, Platanias LC, Giles FJ. Concordance between genomic alterations assessed by next-generation sequencing in tumor tissue or circulating cell-free DNA. Oncotarget. 2016; 7(40):65364-65373. DOI: 10.18632/oncotarget.11692 [PubMed: 27588476]

29. Xie M, Lu C, Wang J, McLellan MD, Johnson KJ, Wendl MC, McMichael JF, Schmidt HK, Yellapantula V, Miller CA, Ozenberger BA, Welch JS, Link DC, Walter MJ, Mardis ER, Dipersio JF, Chen F, Wilson RK, Ley TJ, Ding L. Age-related mutations associated with clonal hematopoietic expansion and malignancies. Nat Med. 2014; 20(12):1472-1478. DOI: 10.1038/nm. 3733 [PubMed: 25326804]

30. Dawson SJ, Tsui DW, Murtaza M, Biggs H, Rueda OM, Chin SF, Dunning MJ, Gale D, Forshew T, Mahler-Araujo B, Rajan S, Humphray S, Becq J, Halsall D, Wallis M, Bentley D, Caldas C, Rosenfeld N. Analysis of circulating tumor DNA to monitor metastatic breast cancer. N Engl J Med. 2013; 368(13):1199-1209. DOI: 10.1056/NEJMoa1213261 [PubMed: 23484797]

31. Van Poznak C, Somerfield MR, Bast RC, Cristofanilli M, Goetz MP, Gonzalez-Angulo AM, Hicks DG, Hill EG, Liu MC, Lucas W, Mayer IA, Mennel RG, Symmans WF, Hayes DF, Harris LN. Use of Biomarkers to Guide Decisions on Systemic Therapy for Women With Metastatic Breast 
Cancer: American Society of Clinical Oncology Clinical Practice Guideline. J Clin Oncol. 2015; 33(24):2695-2704. DOI: 10.1200/JCO.2015.61.1459 [PubMed: 26195705]

32. Haricharan S, Bainbridge MN, Scheet P, Brown PH. Somatic mutation load of estrogen receptorpositive breast tumors predicts overall survival: an analysis of genome sequence data. Breast Cancer Res Treat. 2014; 146(1):211-220. DOI: 10.1007/s10549-014-2991-x [PubMed: 24839032]

33. Olivier M, Langerod A, Carrieri P, Bergh J, Klaar S, Eyfjord J, Theillet C, Rodriguez C, Lidereau R, Bieche I, Varley J, Bignon Y, Uhrhammer N, Winqvist R, Jukkola-Vuorinen A, Niederacher D, Kato S, Ishioka C, Hainaut P, Borresen-Dale AL. The clinical value of somatic TP53 gene mutations in 1,794 patients with breast cancer. Clin Cancer Res. 2006; 12(4):1157-1167. DOI: 10.1158/1078-0432.CCR-05-1029 [PubMed: 16489069]

34. Silwal-Pandit L, Vollan HK, Chin SF, Rueda OM, McKinney S, Osako T, Quigley DA, Kristensen VN, Aparicio S, Borresen-Dale AL, Caldas C, Langerod A. TP53 mutation spectrum in breast cancer is subtype specific and has distinct prognostic relevance. Clin Cancer Res. 2014; 20(13): 3569-3580. DOI: 10.1158/1078-0432.CCR-13-2943 [PubMed: 24803582] 


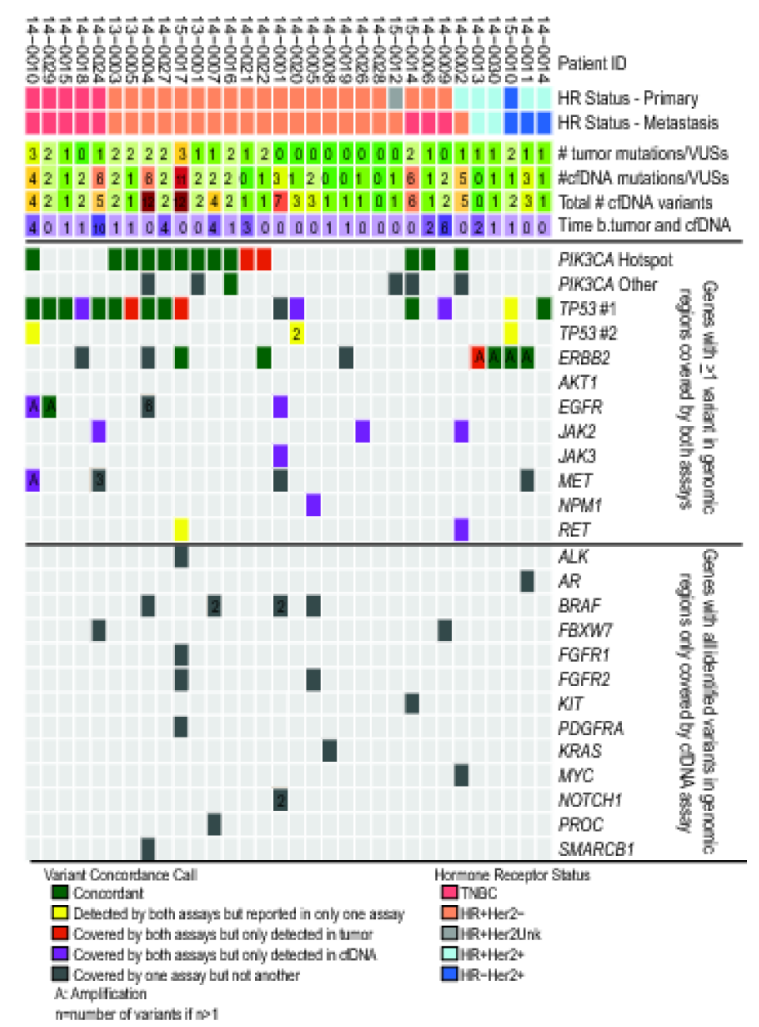

Fig. 1.

Mutational spectra in the tumor/cfDNA cohort. Heat map showing the alterations identified by metastatic tumor testing and cell-free DNA (cfDNA) testing in the tumor/cfDNA cohort. Individual patient identifiers (ID) listed with annotations for receptor status of primary (if applicable) and of the biopsied metastasis. Total number of alterations identified by each assay; tumor assay reports pathogenic mutations and variants of uncertain significance (VUSs) and cfDNA assay reports all variants. Time elapsed between (b.) collection of tumor and blood for respective assays shown in weeks. Only genes shared between both versions of the respective assays are shown (i.e. shared genes on CPD_Full and CPD_PPP for tumor genes and shared genes on GH_v1 and GH_v2 for cfDNA genes) 
a.

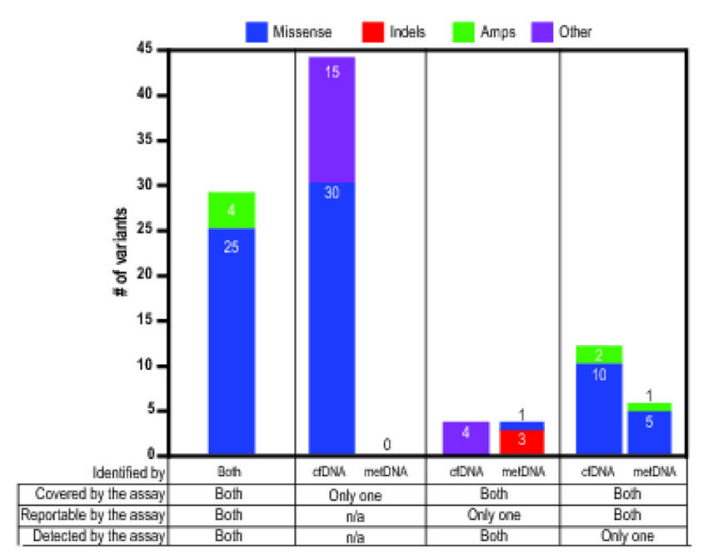

b.

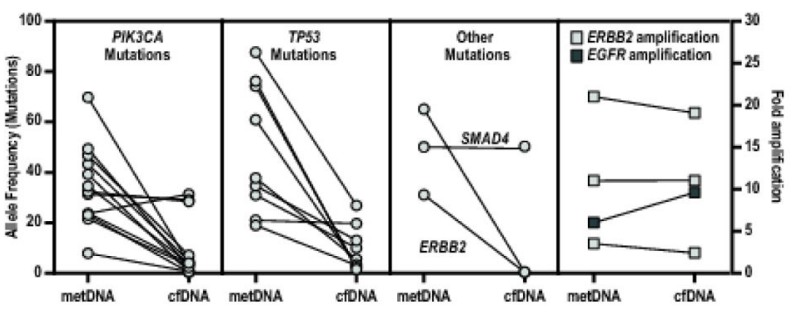

c.

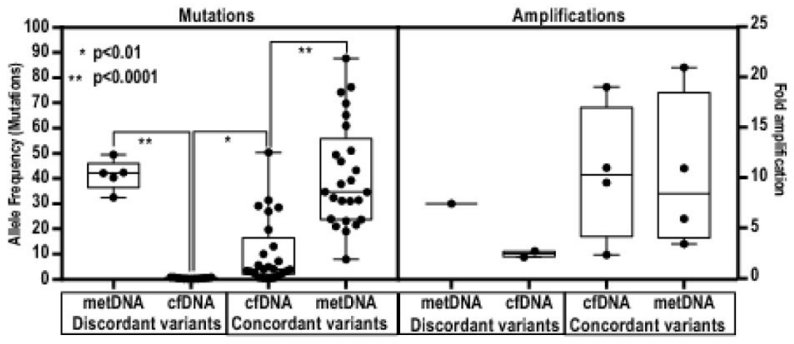

Fig. 2.

Concordance between tumor and cfDNA assays. (a) Bar plot depicting the number of variants concordant (covered, reportable and detected by both assays) in both assays and discordant between tumor and cfDNA assays. Discordant variants plotted within three classes of discordance by the assay by which they were identified. The three types of discordance were variants only covered by one assay, variants covered by both assays but only reportable by one assay, and variants covered and reportable by both assays but only detected by one assay. (b) Plot of paired allele frequencies and paired fold amplifications of individual concordant variants as reported by the tumor and cfDNA assays. (c) Summary of allele frequencies and fold amplifications of discordant variants only identified by tumor or cfDNA assays versus concordant variants. Means of continuous variables compared by a Student's t test 

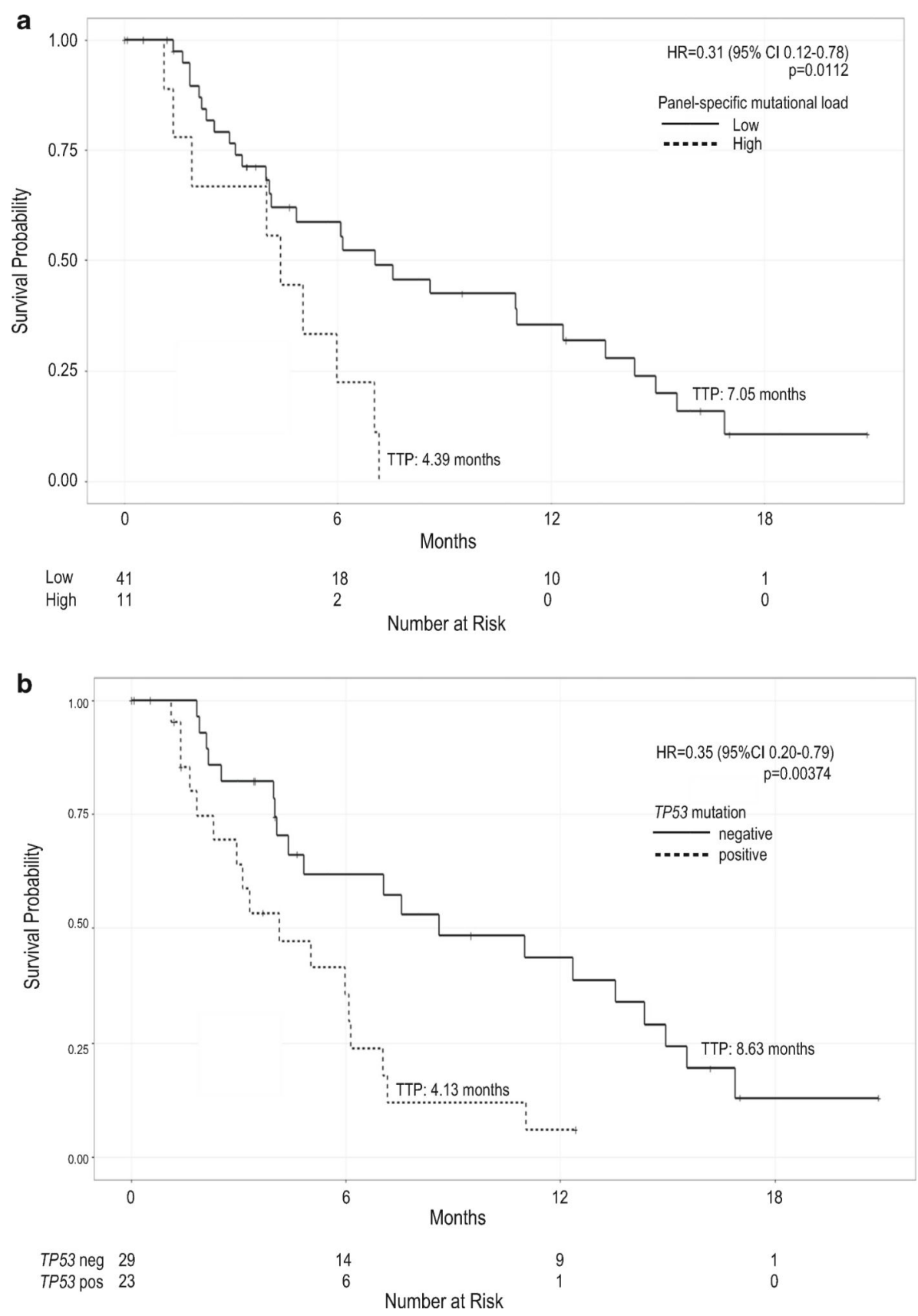

Fig. 3.

Analysis of time to progression on standard treatment stratified by genomic biomarkers. a Patients were stratified into a high mutational load or low mutational load group. Time from initiation of treatment to first progression was analyzed using a Cox proportional-hazard model and adjusting for receptor status of the metastatic biopsy, number of lines of therapy and hormonal treatment versus chemotherapy. b Patients were stratified into a TP53 mutation positive or TP53 mutation negative group. Time from initiation of treatment to first progression was analyzed using a Cox proportional-hazard model and adjusting for receptor 
status of the metastatic biopsy, number of lines of therapy, and hormonal treatment versus chemotherapy 


\section{Table 1}

Characteristics of Study Population

\begin{tabular}{|c|c|c|c|c|}
\hline & \multicolumn{2}{|c|}{ Tumor Cohort } & \multicolumn{2}{|c|}{ Tumor/cfDNA Cohort (subset) } \\
\hline Total number & \multicolumn{2}{|c|}{53} & \multicolumn{2}{|c|}{32} \\
\hline \multirow[t]{2}{*}{ Age (Median, range) } & 56 & $31-79$ & 56 & $33-79$ \\
\hline & $n$ & $\%$ & $N$ & $\%$ \\
\hline \multicolumn{5}{|l|}{ Race } \\
\hline White & 41 & $77 \%$ & 26 & $81 \%$ \\
\hline Black & 9 & $17 \%$ & 6 & $19 \%$ \\
\hline Other/Unknown & 3 & $6 \%$ & 0 & $0 \%$ \\
\hline \multicolumn{5}{|l|}{ Stage at Diagnosis } \\
\hline Stage 0 (DCIS) & 3 & $6 \%$ & 2 & $6 \%$ \\
\hline Stage I & 9 & $17 \%$ & 5 & $16 \%$ \\
\hline Stage II & 16 & $30 \%$ & 10 & $31 \%$ \\
\hline Stage III & 12 & $22 \%$ & 8 & $25 \%$ \\
\hline Stage IV & 13 & $25 \%$ & 7 & $22 \%$ \\
\hline \multicolumn{5}{|c|}{ Receptor Status of Primary ${ }^{I}($ total $n=40 / 25)$} \\
\hline $\mathrm{HR}+/$ Her $2-$ or Her2 unknown & 23 & $58 \%$ & 15 & $60 \%$ \\
\hline HR + or HR-/Her $2+$ & 7 & $18 \%$ & 6 & $24 \%$ \\
\hline HR-/Her2- or Her2 unknown & 10 & $25 \%$ & 4 & $16 \%$ \\
\hline \multicolumn{5}{|c|}{ Receptor Status of Metastases (total $n=53 / 32$ ) } \\
\hline HR+/Her2- or Her2 unknown & 31 & $58 \%$ & 19 & $59 \%$ \\
\hline $\mathrm{HR}+$ or HR-/Her2+ & 7 & $13 \%$ & 5 & $16 \%$ \\
\hline HR-/Her2- or Her2 unknown & 15 & $28 \%$ & 8 & $25 \%$ \\
\hline \multicolumn{5}{|l|}{ Adjuvant Therapy } \\
\hline Received adjuvant hormone $^{2}$ & 21 & $78 \%$ & 14 & $74 \%$ \\
\hline \multirow[t]{2}{*}{ Received adjuvant chemotherapy ${ }^{3}$} & 29 & $97 \%$ & 16 & $94 \%$ \\
\hline & Median & Range & Median & Range \\
\hline \multicolumn{5}{|c|}{ \# prior lines therapy for stage IV disease ${ }^{1}$} \\
\hline $\mathrm{HR}+/ \mathrm{Her} 2-$ or Her 2 unknown & 3 & $0-14$ & 3 & $0-14$ \\
\hline HR + or HR-/Her2+ & 1 & $0-11$ & 1 & $0-6$ \\
\hline HR-/Her2- or Her2 unknown & 2 & $0-9$ & 2 & $0-3$ \\
\hline \multicolumn{5}{|l|}{ Disease-free Interval ${ }^{1}$} \\
\hline HR $+/$ Her $2-$ or Her2 unknown & 122 & $35-502$ & 152 & $50-502$ \\
\hline HR + or HR-/Her $2+$ & 26 & $9-387$ & 266 & $69-387$ \\
\hline HR-/Her2- or Her2 unknown & 70 & $25-761$ & 39 & $25-51$ \\
\hline \multicolumn{5}{|c|}{ Time to progression on subsequent therapy 4} \\
\hline HR $+/$ Her $2-$ or Her2 unknown & 10 & $0-36$ & 12 & $3-34$ \\
\hline HR + or HR-/Her2+ & 16 & $4-40$ & 26 & $6-40$ \\
\hline HR-/Her2- or Her2 unknown & 4 & $1-24$ & 4 & $1-16$ \\
\hline
\end{tabular}

${ }^{1}$ Stage 0-III tumors only, HR status based on primary 
2 Diagnosed Stage 0-III and any HR+ tumors, HR status based on primary; total $\mathrm{n}=27$ and 19

3 Diagnosed Stage 0-III and any HR-Her2, any Her2+, and N1-N3 HR+Her2-; HR status based on primary; total n=30 and 17

${ }^{4}$ HR status based on metastatic lesion 


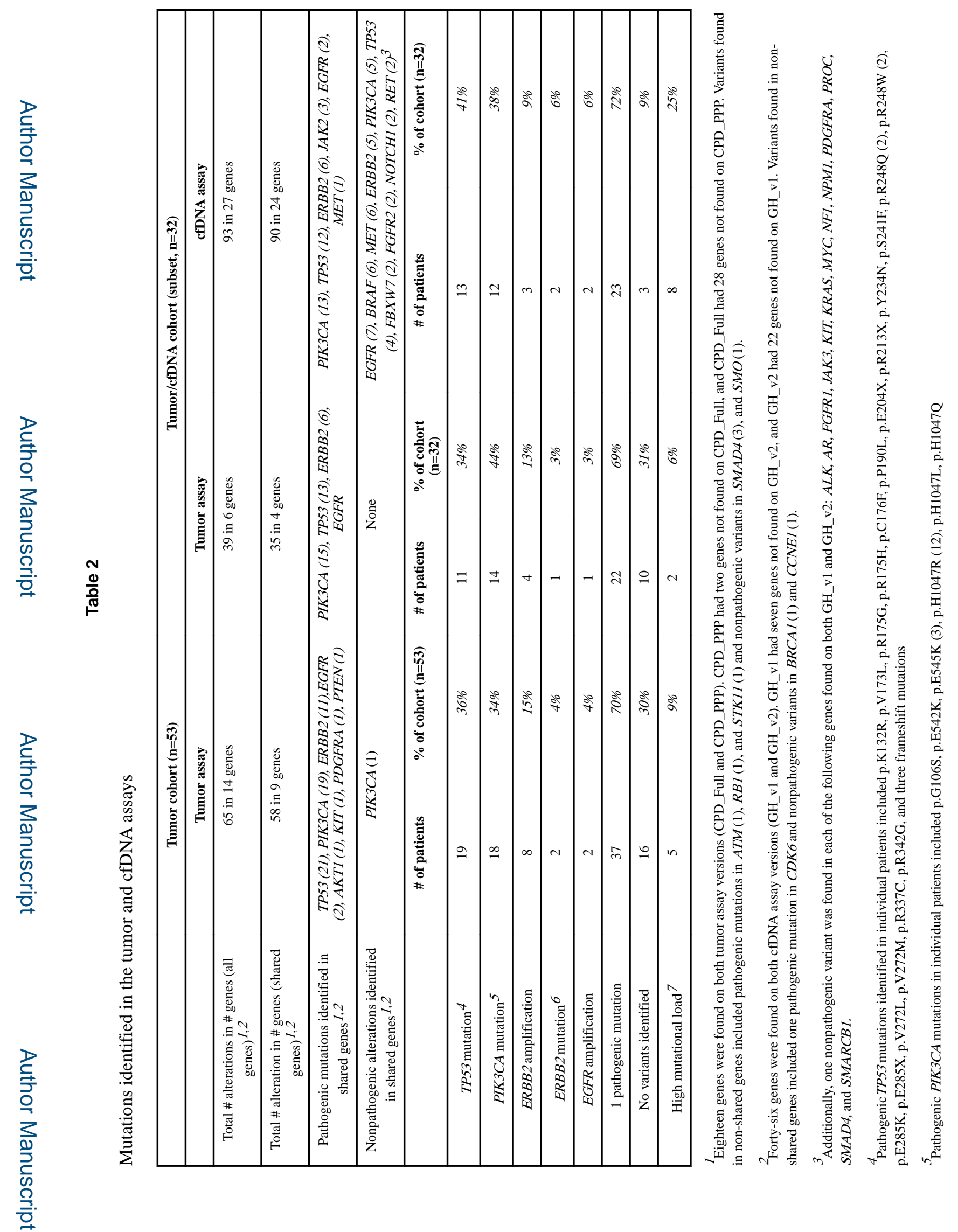

Breast Cancer Res Treat. Author manuscript; available in PMC 2018 August 01. 

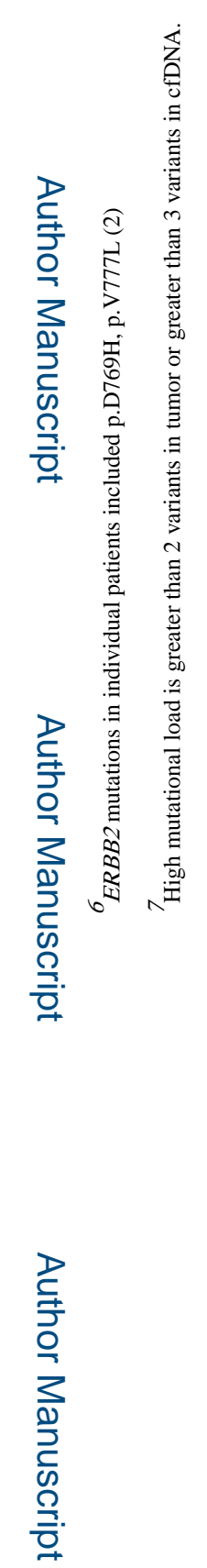

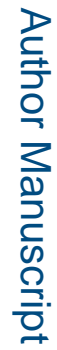

Breast Cancer Res Treat. Author manuscript; available in PMC 2018 August 01. 